\title{
Role Of Neurosonology In Management Of Stroke
}

Farhad Assarzadegan,.

MD, Assistant Professor of Neurology, Shahid Beheshti University of Medical Sciences, Tehran, Iran.

Corresponding Author: Email: assarfarhad@gmail.com

Stroke is one of the most commonly occurring brain diseases and, in spite of its often homogeneous clinical appearance, its causes vary considerably. The implementation of a tailored and targeted therapy in each individual case requires rapid etiological classifi cation and a qualifi ed evaluation of the vascular status. Knowledge of normal vascular anatomy, variants, and anomalies are essential for proper clinical assessment.

In clinical neurology, ultrasound became available in the early 1970s. The neurovascular focus developed in the 1980s with the use of extracranial color-coded duplex sonography (ECCS) and transcranial Doppler (TCD) techniques. The development of transcranial color- coded duplex sonography (TCCS) in the early 1990s was an important advance, as TCCS's diagnostic sensitivity exceeded that of TCD. B-mode and color-mode images generated using TCCS greatly facilitated vessel identifi cation by off ering additional spatial information about vessel courses in relation to bone, parenchymal structures, and ventricles.

In the mid-1990s, routine vascular diagnostic procedures was shifted away from TCD to TCCS. The combination of extra- and intracranial duplex ultrasound permits an almost comprehensive assessment of all brain- supplying vessels with a single bedside device. TCD remains the primary method for functional assessments such as right-left shunt diagnosis, assessment of cerebrovascular reactivity, autoregulation, and bilateral continuous monitoring for spontaneous microemboli.

What is the best diagnostic approach for patients with acute and chronic brain ischemia? Several angiologic methods are now available for the treatment of stroke patients: DSA, MRA, CTA, and ultrasound. Each technique may yield information that is partly competing and partly complementary regarding vessel anatomy, vessel wall properties, and circulation physiology. Stroke physicians should be aware of the strengths and weaknesses of each of the available methods.

Keywords: Neurosonology, Stroke, transcranial color- coded duplex sonography (TCCS)

DOI: $10.7575 /$ aiac.abcmed.ca1.48

A I Published Date: February 2017

Peer-review is under responsibility of the 9th Iranian Stroke Congress.

Published by Australian International Academic Centre, Australia

This published work is open access under the CC BY license.

Available online at www.abcmed.aiac.org.au 